\title{
Association between plasma sRAGE and emphysema according to the genotypes of AGER gene
}

\author{
Sooim Sin ${ }^{1}$, Myung-nam Lim², Jeeyoung Kim², So Hyeon Bak and Woo Jin Kim ${ }^{*}$ (D)
}

\begin{abstract}
Background: Higher soluble receptor for advanced glycation end product (SRAGE) levels are considered to be associated with severe emphysema. However, the relationship remains uncertain when the advanced glycation endproduct specific receptor (AGER) gene is involved. We aimed to analyse the association between sRAGE levels and emphysema according to the genotypes of rs2070600 in the AGER gene.

Methods: We genotyped rs2070600 and measured the plasma concentration of sRAGE in each participant. Emphysema was quantified based on the chest computed tomography findings. We compared sRAGE levels based on the presence or absence and severity of emphysema in each genotype. Multiple logistic and linear regression models were used for the analyses.
\end{abstract}

Results: A total of 436 participants were included in the study. Among them, 64.2\% had chronic obstructive pulmonary disease and $34.2 \%$ had emphysema. Among the CC-genotyped participants, the sRAGE level was significantly higher in participants without emphysema than in those with emphysema $(P<0.001)$. In addition, sRAGE levels were negatively correlated with emphysema severity in CC-genotyped patients $(r=-0.268 P<0.001)$. Multiple regression analysis revealed that sRAGE was an independent protective factor for the presence of emphysema (adjusted odds ratio, $0.24 ; 95 \%$ confidence interval $(\mathrm{Cl}) 0.11-0.51)$ and severity of emphysema $(\beta=-3.28,95 \% \mathrm{Cl}-4.86$ to -1.70$)$ in CC-genotyped participants.

Conclusion: Plasma sRAGE might be a biomarker with a protective effect on emphysema among CC-genotyped patients of rs 2070600 on the AGER gene. This is important in determining the target group for the future prediction and treatment of emphysema.

Keywords: Glycation end-product, Advanced, Receptor for advanced glycation end products, Pulmonary disease, Chronic obstruction, Pulmonary emphysema, Soluble receptor for advanced glycation end product

\section{Background}

Chronic obstructive lung disease (COPD), a major cause of death worldwide, is characterised by chronic airflow limitation due to small airway disease and emphysema

\footnotetext{
*Correspondence: pulmo2@kangwon.ac.kr

${ }^{1}$ Department of Internal Medicine, School of Medicine, Kangwon

National University Hospital, Kangwon National University,

Chuncheon 24341, Republic of Korea

Full list of author information is available at the end of the article
}

[1]. In addition to its association with COPD, emphysema is an independent predictor of mortality $[2,3]$. Consequently, soluble receptor for advanced glycation end product (sRAGE) levels have gained prominence as biomarkers of emphysema. Several studies have shown that low levels of sRAGE are associated with emphysema and severe emphysema [4-6]. In addition, progression of emphysema is related to sRAGE levels [7]. 
RAGE, a multiligand transmembrane receptor, is highly expressed in normal lung tissues and regulates inflammatory pathways [8]. Chronic inflammatory diseases, including diabetes mellitus, arthritis, and cardiovascular diseases, are associated with the RAGE pathway [9-11]. Likewise, a number of studies have demonstrated a relationship between RAGE and emphysema [12-14]. Furthermore, genome-wide association studies (GWASs) have shown that the RAGE gene for the advanced glycation end-product specific receptor, $A G E R$, which generates RAGE and consequently sRAGE, is associated with either COPD or emphysema $[15,16]$. Among the multiple variants of $A G E R$, rs 2070600 is a particularly notable sentinel variant related to emphysema. The minor allele of rs2070600 was identified to be associated with better lung function, low risk of COPD, decreased quantification of emphysema, and low sRAGE levels.

Thus, these findings suggest that high levels of sRAGE have a protective effect on the risk of emphysema. However, the minor allele of rs2070600 is simultaneously related to low levels of sRAGE and a decreased risk of emphysema. This study sought to evaluate the relationship between sRAGE and emphysema according to the rs2070600 polymorphism. We hypothesised that the association between sRAGE and emphysema is different for each rs2070600 polymorphism.

\section{Methods}

\section{Study population}

A total of 504 participants from the COPD in the dusty area (CODA) cohort were enrolled from January 2012 to December 2017 (Fig. 1). CODA is a prospective cohort composed of patients with airflow limitation and healthy volunteers residing in the Kangwon and Chungbuk provinces of South Korea. The details of the cohorts have been described previously $[17,18]$. Clinical information, including medical history, subjective symptoms, and lung function results, was assessed by medical interviews, questionnaires, physical examinations, and spirometry. Patients with a post-bronchodilator forced expiratory volume in $1 \mathrm{~s}\left(\mathrm{FEV}_{1}\right)$ to forced vital capacity (FVC) ratio below 0.7 at baseline were defined as having COPD [1]. Patients with COPD were divided into stages 1 to 4 according to airflow limitation based on the Global Initiative for Chronic Obstructive Lung Disease (GOLD) guidelines [1].

Written informed consent was obtained from all participants. This study was approved by the Institutional Review Board of the Kangwon National University Hospital (IRB No. KNUH 2012-06-007).

\section{Emphysema quantification}

All participants underwent volumetric thin-section chest computed tomography ( $\mathrm{CT}$ at full inspiration in the supine position. CT images were obtained using a dual-source CT scanner (Somatom Definition; Siemens

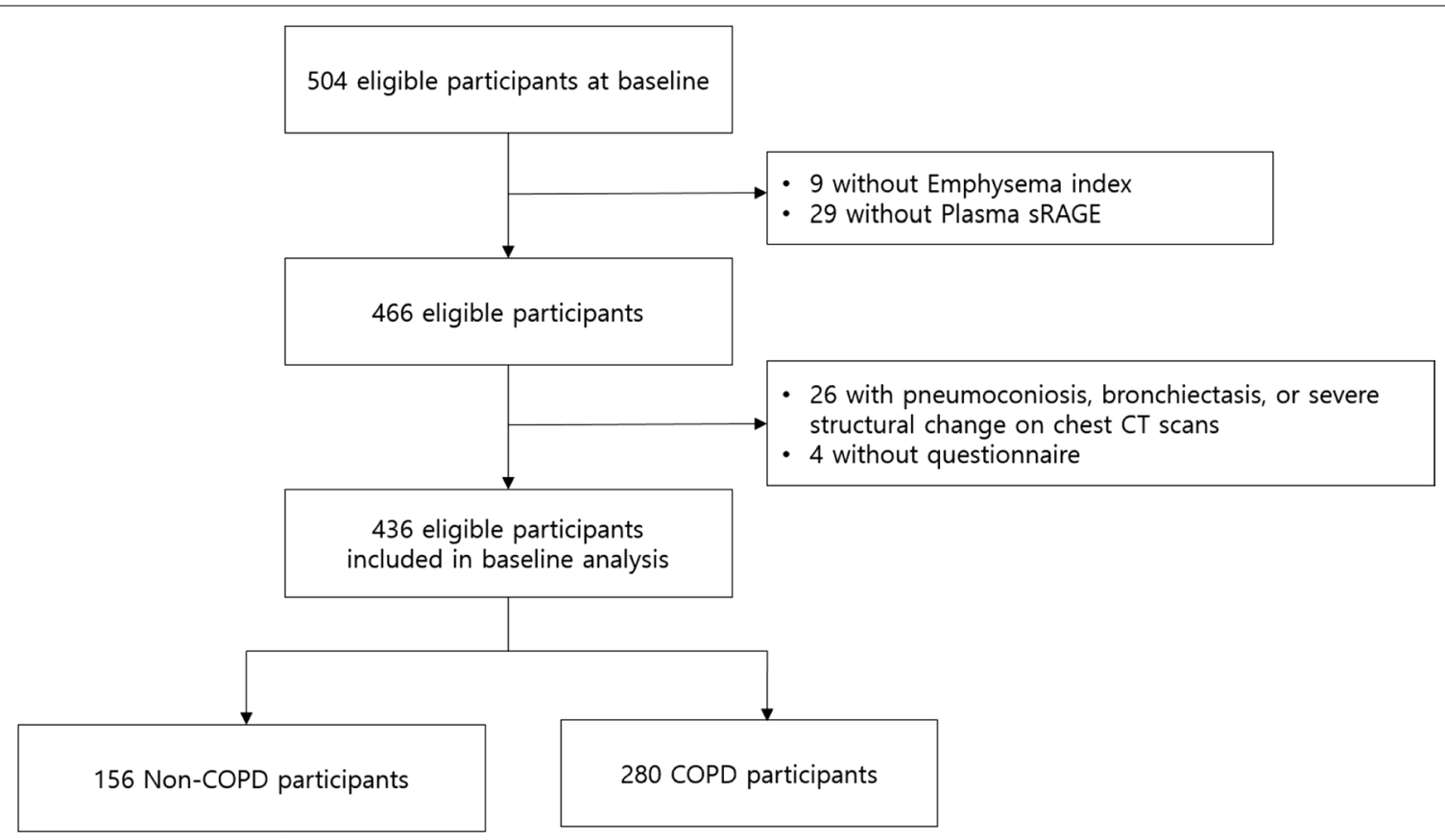

Fig. 1 Flow chart of the study 
Healthcare, Forchheim, Germany). Quantification was performed using the Aview ${ }^{\circledR}$ system (Coreline Soft Inc.). We quantified emphysema which was defined as lung parenchyma below the -950 Hounsfield unit threshold on CT images $[19,20]$. The quantified emphysema was used as a continuous variable and the emphysema index. In addition, as a categorical variable, the presence or absence of emphysema was based on an emphysema index of $5 \%$ of the total lung area, as defined in previous studies $[21,22]$. The detailed methodology of the CT protocols has been previously published [23].

\section{Measurement of plasma sRAGE levels}

Plasma samples were obtained from the participants to quantify sRAGE levels using a commercially available enzyme-linked immunosorbent assay (ELISA) (human RAGE Quantikine ${ }^{\circledR}$ ELISA Kit SRG00; R\&D System, Minneapolis, MN, USA), according to the manufacturer's instructions. The ELISA plates were read using a microplate reader (Molecular Devices, Sunnyvale, CA, USA).

\section{Genotyping of rs2070600}

Genotyping was performed using blood samples from the Asian Precision Medicine Research Array (APMRA, Afymetrix, CA, USA). DNA samples were hybridised to an array in the GeneTitan MC Instrument (Afymetrix) according to the GeneTitan ${ }^{\circledR}$ Multichannel Instrument User's Manual, using the Axiom APMRA 96-ARRAY. After ligation, the arrays were stained and imaged using a GeneTitan MC instrument (Afymetrix).

\section{Statistical analysis}

Data were analysed using the chi-square test for categorical variables and Student's t-test for continuous variables. The relationships between the two continuous parameters were evaluated using the Pearson's correlation coefficients. Multiple logistic and linear regression analyses were performed to adjust for covariates which were clinically important or statistically significant in the univariate analyses. Log-transformed sRAGE was used for the statistical analysis. Statistical significance was defined as a two-sided $P$-value $<0.05$. Statistical analyses were conducted using SAS (version 9.4; SAS Institute, Cary, NC, USA) and R (version 3.2.3 (The R Foundation for Statistical Computing, Vienna, Austria, http://www.Rproject. org).

\section{Results}

\section{Demographics of the study population}

Among the 504 eligible participants, 436 were included in the analysis (Fig. 1). The baseline demographics of the study participants are shown in Table 1 . The mean
Table 1 Baseline demographics and comparison of demographics according to genotypes

\begin{tabular}{|c|c|c|c|c|}
\hline & $\begin{array}{l}\text { Total } \\
\mathrm{N}=436\end{array}$ & $\begin{array}{l}\text { CC* } \\
n=290\end{array}$ & $\begin{array}{l}\mathrm{TC}+\mathrm{TT}^{*} \\
\mathrm{n}=146\end{array}$ & $P$ \\
\hline Age, years & $72.3 \pm 7.1$ & $72.4 \pm 7.1$ & $72.2 \pm 7.2$ & 0.710 \\
\hline Sex, male, n (\%) & $316(72.5)$ & $218(75.2)$ & $98(67.1)$ & 0.075 \\
\hline $\begin{array}{l}\text { Emphysema } \\
\text { index }\end{array}$ & $5.6 \pm 6.3$ & $6.5 \pm 0.3$ & $4.7 \pm 0.5$ & 0.002 \\
\hline $\begin{array}{l}\text { Presence of } \\
\text { emphysema }\end{array}$ & & & & 0.020 \\
\hline $\begin{array}{l}\text { Emphysema } \\
(-)\end{array}$ & $287(65.8)$ & $180(62.1)$ & $107(73.3)$ & \\
\hline $\begin{array}{l}\text { Emphysema } \\
(+)\end{array}$ & $149(34.2)$ & $110(37.9)$ & $39(26.7)$ & \\
\hline COPD, n (\%) & & & & 0.040 \\
\hline Non-COPD & $156(35.8)$ & $93(32.0)$ & $63(43.2)$ & \\
\hline GOLD Stage 1 & $20(4.6)$ & $12(4.1)$ & $8(5.5)$ & \\
\hline GOLD Stage 2 & $143(32.8)$ & $92(31.7)$ & $51(34.9)$ & \\
\hline GOLD Stage 3 & $118(27.0)$ & $90(31.0)$ & $28(18.2)$ & \\
\hline $\begin{array}{l}\text { Smoking status, } \\
\text { n (\%) }\end{array}$ & & & & 0.046 \\
\hline Current & $96(22.1)$ & $72(24.9)$ & $24(16.5)$ & \\
\hline Former & $180(41.5)$ & $122(42.2)$ & $58(40.0)$ & \\
\hline Never & $158(36.4)$ & $95(32.9)$ & $63(43.5)$ & \\
\hline $\begin{array}{l}\text { Smoking, Pack- } \\
\text { years }\end{array}$ & $17.1 \pm 22.8$ & $18.1 \pm 22.4$ & $15.2 \pm 23.6$ & 0.223 \\
\hline Education & & & & 0.304 \\
\hline $\begin{array}{l}\text { < Elementary } \\
\text { school }\end{array}$ & $132(31.1)$ & $90(31.9)$ & $42(29.4)$ & \\
\hline $\begin{array}{l}\text { Elementary } \\
\text { school }\end{array}$ & $164(38.6)$ & $101(35.8)$ & $63(44.0)$ & \\
\hline Middle school & $63(14.8)$ & $38(13.5)$ & $25(17.5)$ & \\
\hline$\geq$ High school & $66(15.5)$ & $53(18.8)$ & $13(9.1)$ & \\
\hline sRAGE, pg/mL & $666.7 \pm 338.8$ & $720.9 \pm 341.4$ & $558.9 \pm 307.5$ & $<0.001$ \\
\hline Log sRAGE & $6.4 \pm 0.4$ & $6.4 \pm 0.4$ & $6.2 \pm 0.5$ & $<0.001$ \\
\hline
\end{tabular}

Categorical variables are expressed as number (\%) and continuous variables are expressed as mean \pm standard deviation

COPD chronic obstructive pulmonary disease, sRAGE soluble receptor for advanced glycation end products

*Genotypes of rs2060700

age of the participants was 72.3 years, and $316(72.5 \%)$ were male. The number of COPD patients was 280 (64.2\%), and among the COPD patients, 143 (51.1\%), 118 (42.1\%), and 19 (6.8\%) were classified into stages 1,2 , and 3, respectively. Overall, 146 (33.5\%) participants had either TC or TT genotypes at rs2070600, and 149 (34.2\%) participants had emphysema (emphysema index $>6 \%$ ) on chest CT.

No significant differences were observed in the mean age or sex distribution according to the different polymorphisms of rs2070600. Participants with the CC genotype had more severe emphysema and COPD than those with the $\mathrm{T}$ allele (Table 1 ). The log-transformed 
Table 2 Emphysema status according to plasma sRAGE level in each genotype

\begin{tabular}{|c|c|c|c|c|c|c|}
\hline & \multicolumn{2}{|l|}{ Total } & \multicolumn{2}{|l|}{$\mathrm{CC}^{*}$} & \multicolumn{2}{|l|}{$\mathrm{TC}+\mathrm{TT}^{*}$} \\
\hline & SRAGE & $P$ & sRAGE & $P$ & sRAGE & $P$ \\
\hline Emphysema (-) & $6.44 \pm 0.47$ & & $6.58 \pm 0.41$ & & $6.21 \pm 0.48$ & \\
\hline Emphysema (+) & $6.32 \pm 0.40$ & 0.006 & $6.37 \pm 0.38$ & $<0.001$ & $6.21 \pm 0.45$ & 0.976 \\
\hline
\end{tabular}

Levels of sRAGE are log transformed and expressed as mean \pm standard deviation SRAGE soluble receptor for advanced glycation end product

*Genotypes of rs2060700

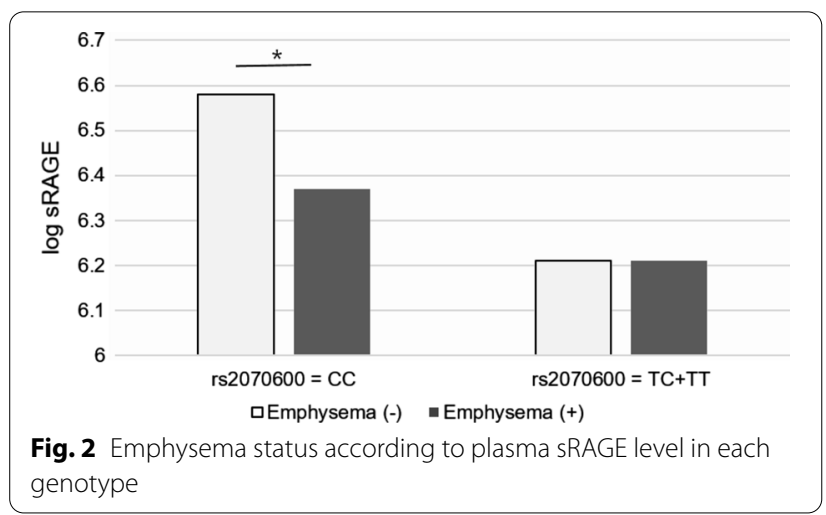

sRAGE levels followed a normal distribution (Additional file 1: Fig. 1).

\section{Emphysema status according to plasma sRAGE level in each genotype}

We grouped the participants according to the rs2070600 polymorphism. Plasma sRAGE levels in the presence or absence of emphysema were compared in each genotype group. The sRAGE level was significantly higher in participants without emphysema than in those with emphysema in all participants $(P=0.006)$. Similarly, in the CC genotyped group, sRAGE levels were significantly higher in participants without emphysema than in those with emphysema $(P<0.001)$. However, there was no difference in sRAGE levels between the participants with and without emphysema among the $\mathrm{T}$ allele-containing genotype group (Table 2, Fig. 2).

\section{Correlation between emphysema index and sRAGE}

In the correlation analysis, the sRAGE level was negatively correlated with the emphysema index in all participants $(\mathrm{r}=-0.146, P=0.002)$. Interestingly, when we divided the participants according to genotype, this correlation was only significant in $\mathrm{CC}$-genotyped participants $(\mathrm{r}=-0.268, P<0.001)$. In the $\mathrm{T}$-allele-containing genotype group, there was no clear correlation between sRAGE and emphysema (Table 3). This correlation was also observed in the scatter plot (Fig. 3).

\section{Multiple regression analyses for emphysema}

To identify the risk factors, logistic regression analyses for the risk of emphysema were conducted for each genotype group. In the multiple logistic model, male sex and COPD were risk factors for emphysema, and sRAGE was a protective factor for emphysema in CC genotyped participants (aOR for log sRAGE 0.24; 95\% CI, 0.11-0.51), whereas sRAGE was not significantly associated with the $\mathrm{T}$ allele (Table 4). In addition, linear regression analyses for the severity of emphysema were conducted for

Table 3 Correlation between sRAGE and lung function or emphysema in each genotype

\begin{tabular}{|c|c|c|c|c|c|c|}
\hline & \multicolumn{2}{|l|}{$\begin{array}{l}\text { Total } \\
\mathrm{N}=436\end{array}$} & \multicolumn{2}{|l|}{$\begin{array}{l}C C^{*} \\
n=290\end{array}$} & \multicolumn{2}{|l|}{$\begin{array}{l}\mathrm{TC}+\mathrm{TT}^{*} \\
\mathrm{n}=146\end{array}$} \\
\hline & \multicolumn{6}{|c|}{ Log sRAGE } \\
\hline & $r$ & $P$ & $r$ & $P$ & $r$ & $P$ \\
\hline Post-BD FVC (L) & -0.034 & 0.478 & -0.059 & 0.314 & -0.021 & 0.800 \\
\hline Post-BD FEV ${ }_{1}(\mathrm{~L})$ & -0.004 & 0.931 & 0.011 & 0.848 & -0.001 & 0.990 \\
\hline Post-BD FEV $1 / F V C(\%)$ & 0.034 & 0.484 & 0.118 & 0.045 & 0.003 & 0.968 \\
\hline Emphysema index & -0.146 & 0.002 & -0.268 & $<0.001$ & -0.017 & 0.836 \\
\hline
\end{tabular}

SRAGE soluble receptor for advanced glycation end product, $B D$ bronchodilator, $F V$ C forced vital capacity, $F E V$, forced expiratory volume in $1 \mathrm{~s}$

*Genotypes of rs 2060700 


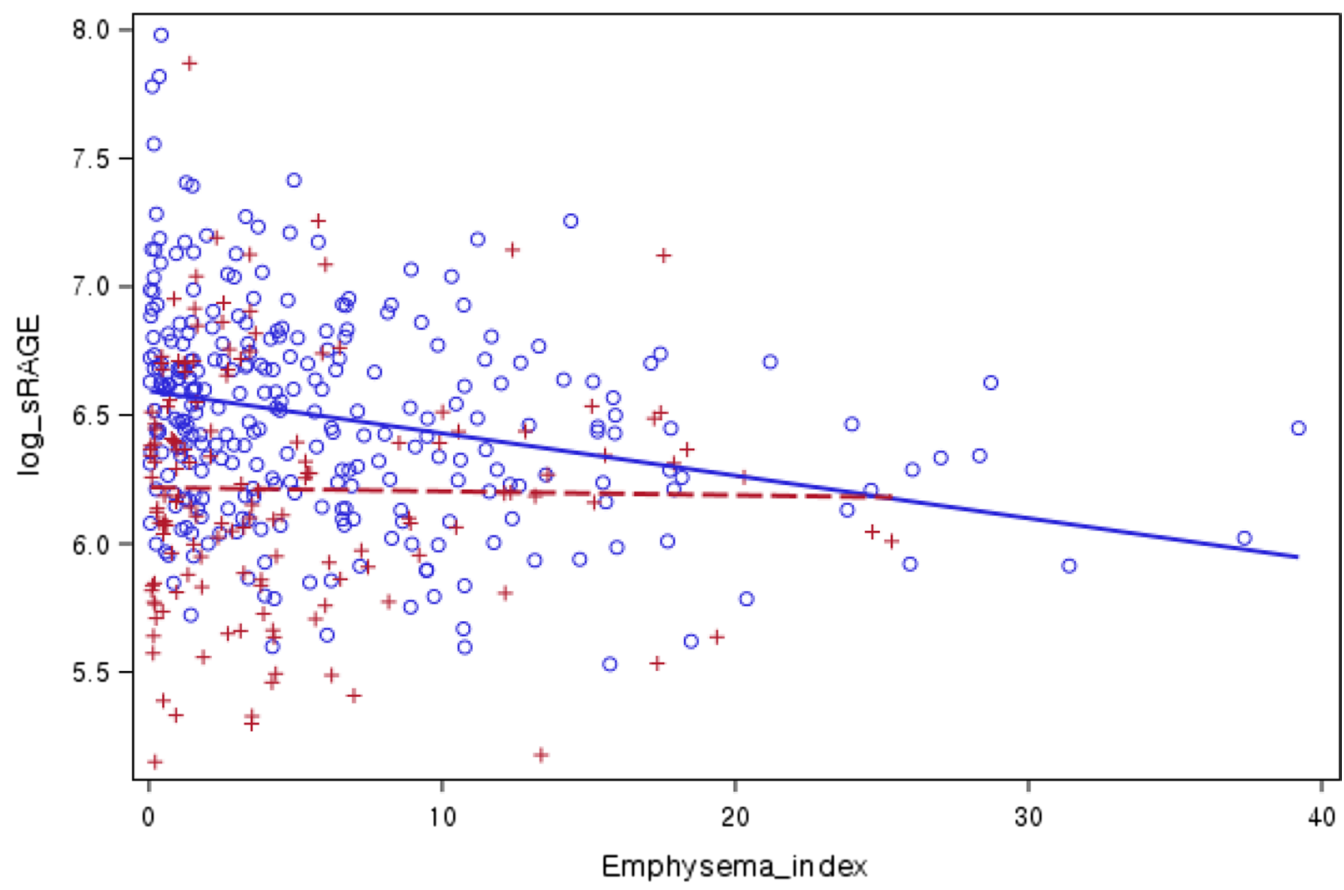

rs $-\mathrm{CC}---\mathrm{TT}$

Fig. 3 Scatter plot presenting correlation between SRAGE and lung function or emphysema in each genotype. CC genotype group, $r=-0.268$ and $P<0.001 ; \mathrm{TC}+\mathrm{TT}$ genotype group, $r=-0.017$ and $P=0.836$

each genotype group. Multiple linear regression analysis showed that the level of sRAGE had a negative correlation with the emphysema index in CC genotyped participants ( $\beta=-3.28 ; 95 \% \mathrm{CI},-4.86$ to -1.70 ), while the level of sRAGE showed no relationship in participants with the $\mathrm{T}$ allele (Table 5 ).

\section{Discussion}

The principal finding of our study was that the rs 2070600 polymorphism affected the relationship between emphysema and plasma sRAGE. In participants with the CC allele of rs2070600, plasma sRAGE had a protective effect on emphysema, whereas this effect was not observed in participants with the $\mathrm{T}$ allele. Moreover, in participants with the CC allele of rs2070600, the level of plasma sRAGE was negatively correlated with emphysema severity, whereas this correlation was not observed in those with the $\mathrm{T}$ allele.

RAGE is a receptor implicated in the mediation and amplification of proinflammatory responses [24]. Pulmonary inflammation through RAGE induces emphysematous changes in animal models $[25,26]$. As a soluble extracellular decoy receptor for RAGE, sRAGE protects cells against inflammation and tissue injury. Inhibition of RAGE by sRAGE reduces acute lung injury in an animal model [27].
A number of studies have shown that sRAGE levels are not only decreased in patients with emphysema, but also negatively correlated with the severity of emphysema $[4,6,7]$. Moreover, the progression of emphysema is associated with sRAGE [7]. These studies were based on large populations and validated cohorts such as the Treatment of Emphysema with a Selective Retinoid Agonist (TESRA), Evaluation of COPD Longitudinally to Identify Predictive Surrogate Endpoints (ECLIPSE), and COPDGene cohorts. The results of our study are consistent with those of previous studies. We confirmed that sRAGE levels were significantly lower in participants with emphysema and showed a significant negative relationship with the severity of emphysema. This is the first time that the relationship has been proven in an Asian population. In terms of genetics, the plasma levels of sRAGE were greater in participants with the CC allele than in those with the $\mathrm{T}$ allele of rs2070600 [21, 28]. This finding has also been identified in various populations, including Koreans [29]. In this study, we confirmed this relationship between the allele of rs2070600 and levels of sRAGE. In addition, previous GWASs have identified that the T allele of rs2070600 is associated with a lower risk of emphysema $[15,30]$. Our results show that a lower proportion of patients with emphysema and a lower emphysema index in the $\mathrm{T}$ allele group also supports 
Table 4 Logistic regression model for emphysema

\begin{tabular}{|c|c|c|c|}
\hline & & $\begin{array}{l}\text { Univariable } \\
\text { OR }(95 \% \mathrm{Cl})\end{array}$ & $\begin{array}{l}\text { Multivariable } \\
\text { aOR }(95 \% \mathrm{Cl})\end{array}$ \\
\hline \multicolumn{4}{|l|}{$\mathrm{rs} 2070600=\mathrm{CC}$} \\
\hline Age & & $1.02(0.98-1.05)$ & $1.00(0.96-1.05)$ \\
\hline Sex & Male vs. Female (ref.) & $10.04(4.18-24.12)$ & $5.40(1.53-19.11)$ \\
\hline \multirow[t]{2}{*}{ Smoking status } & Current vs. None (ref.) & $5.85(2.73-12.55)$ & $0.85(0.27-2.62)$ \\
\hline & Former vs. None (ref.) & $7.63(3.78-15.40)$ & $2.03(0.73-5.62)$ \\
\hline \multirow[t]{2}{*}{ Income } & $\leq 49$ vs. $\geq 100$ (ref.) & $1.33(0.72-2.45)$ & \\
\hline & $50-99$ vs. $\geq 100$ (ref.) & $1.74(0.77-3.89)$ & \\
\hline \multirow[t]{3}{*}{ Education } & < Elementary vs. high (ref.) & $0.38(0.19-0.77)$ & \\
\hline & Elementary vs. high (ref.) & $0.59(0.30-1.15)$ & \\
\hline & Middle vs. high (ref.) & $0.46(0.20-1.10)$ & \\
\hline BMI & & $0.79(0.72-0.87)$ & $0.79(0.70-0.88)$ \\
\hline COPD & Yes vs. No (ref.) & $4.39(2.39-8.06)$ & $2.97(1.53-5.79)$ \\
\hline Diabetes & Yes vs. No (ref.) & $0.65(0.31-1.38)$ & \\
\hline Kidney disease & Yes vs. No (ref.) & $0.01(0.001-999.9)$ & \\
\hline$C V D^{*}$ & Yes vs. No (ref.) & $0.71(0.31-1.61)$ & \\
\hline Log sRAGE & & $0.23(0.12-0.44)$ & $0.24(0.11-0.51)$ \\
\hline \multicolumn{4}{|c|}{ rs $2070600=T C+T T$} \\
\hline Age & & $1.01(0.96-1.06)$ & $1.02(0.95-1.09)$ \\
\hline Sex & Male vs. Female (ref.) & $10.00(0.01-35.82)$ & $5.11(0.01-21.99)$ \\
\hline \multirow[t]{2}{*}{ Smoking status } & Current vs. None (ref.) & $10.54(2.88-38.57)$ & $1.54(0.33-7.14)$ \\
\hline & Former vs. None (ref.) & $10.41(3.33-32.54)$ & $1.65(0.42-6.41)$ \\
\hline \multirow[t]{2}{*}{ Income } & $\leq 49$ vs. $\geq 100$ (ref.) & $0.38(0.15-0.97)$ & \\
\hline & $50-99$ vs. $\geq 100$ (ref.) & $0.46(0.14-1.52)$ & \\
\hline \multirow[t]{3}{*}{ Education } & $<$ Elementary vs. high (ref.) & $0.10(0.03-0.36)$ & \\
\hline & Elementary vs. high (ref.) & $0.29(0.11-0.77)$ & \\
\hline & Middle vs. high (ref.) & $0.79(0.21-3.03)$ & \\
\hline BMI & & $0.77(0.67-0.88)$ & $0.77(0.65-0.91)$ \\
\hline COPD & Yes vs. No (ref.) & $6.27(2.43-16.20)$ & $4.46(1.58-12.58)$ \\
\hline Diabetes & Yes vs. No (ref.) & $1.01(0.41-2.51)$ & \\
\hline Kidney disease & Yes vs. No (ref.) & $4.00(0.85-18.88)$ & \\
\hline CVD & Yes vs. No (ref.) & $0.47(0.15-1.47)$ & \\
\hline Log sRAGE & & $0.77(0.35-1.70)$ & $0.61(0.23-1.61)$ \\
\hline
\end{tabular}

OR, odds ratio; BMI, body mass index; COPD, chronic obstructive pulmonary disease; CVD, cardiovascular disease; SRAGE, soluble receptor for advanced glycation end product

previous findings. Combining these proven associations, the paradoxical effect of the $\mathrm{T}$ allele of rs 2070600 remains an unsolved problem. The minor allele $(\mathrm{T})$ of rs2070600 was associated with a lower risk of emphysema and was simultaneously associated with lower sRAGE levels, which are linked to a high risk of emphysema. In our study, the results of the statistical analysis after grouping the subjects according to the genotype of rs2060700 presented novel insights. Contrary to the statistically significant trends in the overall population, the relationship between sRAGE and emphysema in a minority of the participants, the minor allele group, was not significant. The relationship between sRAGE and emphysema, which was definitely different in the minority group, may have been considered the same as the relationship identified in the majority due to the small number of the minor group in previous cohort studies.

Although GWAS revealed the association between $A G E R$ gene polymorphisms and emphysema, the underlying pathogenic mechanism is unknown. The RAGE axis is difficult to explain simply because the $A G E R$ gene affects both RAGE and sRAGE, and simultaneously, sRAGE also affects signalling through RAGE. Here, we suggest the following hypothesis: the $A G E R$ gene may be involved in the function of RAGE, as well as the concentration of sRAGE. For example, as in previous functional 
Table 5 Linear regression model for severity of emphysema

\begin{tabular}{|c|c|c|c|}
\hline & & $\begin{array}{l}\text { Univariable } \\
\text { beta }(95 \% \mathrm{Cl})\end{array}$ & $\begin{array}{l}\text { Multivariable } \\
\text { beta }(95 \% \mathrm{Cl})\end{array}$ \\
\hline \multicolumn{4}{|l|}{ rs $2070600=C C$} \\
\hline Age & & $0.09(-0.02-0.20)$ & $0.03(-0.06-0.13)$ \\
\hline Sex & Male vs. Female (ref.) & $5.42(3.74-7.09)$ & $1.90(-0.55-4.35)$ \\
\hline \multirow[t]{2}{*}{ Smoking status } & Current vs. None (ref.) & $5.15(3.26-7.05)$ & $0.81(-1.77-3.40)$ \\
\hline & Former vs. None (ref.) & $5.78(4.13-7.44)$ & $2.81(0.45-5.17)$ \\
\hline \multirow[t]{2}{*}{ Income } & $\leq 49$ vs. $\geq 100$ (ref.) & $0.64(-1.24-2.52)$ & \\
\hline & $50-99$ vs. $\geq 100$ (ref.) & $2.56(0.02-5.10)$ & \\
\hline \multirow[t]{3}{*}{ Education } & $<$ Elementary vs. high (ref.) & $-3.11(-5.29$ to -0.93$)$ & \\
\hline & Elementary vs. high (ref.) & $-1.68(-3.81-0.46)$ & \\
\hline & Middle vs. high (ref.) & $-1.82(-4.50-0.86)$ & \\
\hline BMI & & $-0.81(-1.06$ to -0.56$)$ & $-0.63(-0.87$ to -0.38$)$ \\
\hline COPD & Yes vs. No (ref.) & $4.78(3.21-6.34)$ & $2.87(1.4-4.31)$ \\
\hline Diabetes & Yes vs. No (ref.) & $-1.93(-4.15-0.30)$ & \\
\hline Kidney disease & Yes vs. No (ref.) & $-3.29(-10.66-4.07)$ & \\
\hline$C V D^{*}$ & Yes vs. No (ref.) & $-1.74(-4.22-0.75)$ & \\
\hline Log sRAGE & & $-4.37(-619$ to -2.55$)$ & $-3.28(-4.86$ to -1.70$)$ \\
\hline \multicolumn{4}{|c|}{ rs $2070600=T C+T T$} \\
\hline Age & & $0.04(-0.09-0.16)$ & $0.002(-0.10-0.11)$ \\
\hline Sex & Male vs. Female (ref.) & $5.14(3.39-6.89)$ & $1.94(-0.58-4.46)$ \\
\hline \multirow[t]{2}{*}{ Smoking status } & Current vs. None (ref.) & $3.43(1.09-5.77)$ & $0.50(-2.34-3.34)$ \\
\hline & Former vs. None (ref.) & $5.28(3.50-7.05)$ & $2.44(-0.02-4.91)$ \\
\hline \multirow[t]{2}{*}{ Income } & $\leq 49$ vs. $\geq 100$ (ref.) & $-1.53(-3.97-0.90)$ & \\
\hline & $50-99$ vs. $\geq 100$ (ref.) & $-1.56(-4.66-1.53)$ & \\
\hline \multirow[t]{3}{*}{ Education } & $<$ Elementary vs. high (ref.) & $-4.34(-7.73$ to -0.94$)$ & \\
\hline & Elementary vs. high (ref.) & $-2.96(-6.21-0.30)$ & \\
\hline & Middle vs. high (ref.) & $-1.83(-5.49-1.83)$ & \\
\hline BMI & & $-0.57(-0.81$ to -0.34$)$ & $-0.43(-0.65$ to -0.22$)$ \\
\hline COPD & Yes vs. No (ref.) & $4.15(2.44-5.86)$ & $2.57(1.00-4.15)$ \\
\hline Diabetes & Yes vs. No (ref.) & $-0.34(-2.58-1.90)$ & \\
\hline Kidney disease & Yes vs. No (ref.) & $3.62(-0.56-7.80)$ & \\
\hline CVD & Yes vs. No (ref.) & $-2.16(-4.54-0.21)$ & \\
\hline Log sRAGE & & $-0.20(-2.15-1.75)$ & $-1.15(-2.76-0.45)$ \\
\hline
\end{tabular}

OR odds ratio, $B M I$ body mass index, COPD chronic obstructive pulmonary disease, CVD cardiovascular disease; sRAGE soluble receptor for advanced glycation end product

studies on RAGE, the binding affinity of sRAGE to RAGE may differ among alleles. The high binding affinity of sRAGE to RAGE in the participants with the $T$ allele effectively blocked inflammatory signals through RAGE and prevented the development and progression of emphysema despite the low level of sRAGE in the participants with the $T$ allele. In contrast, a low binding affinity would result in various degrees of RAGE blockade depending on the sRAGE level. Additional experimental research is needed to elucidate the pathogenic mechanisms associated with $A G E R$.

The study by Pratte et al. also showed significant differences in the level of sRAGE according to genotype of rs2070600, and the level was higher in the CC genotype than in the minor allele genotypes which is in line with our study results [31]. Distinct from the study which focused on the interaction of genotype on the correlation of sRAGE and emphysema, we focused on the individual correlation between sRAGE and emphysema in each genotype. Therefore, our results suggest that the unique and significant association between sRAGE and emphysema in the CC genotype may have clinical value which should not be overlooked. The $\mathrm{p}$ value for the interaction of rs2070600 genotype on the correlation between sRAGE and emphysema failed to achieve statistical significance in our study. However, there are limitations in 
interpreting the results of the interaction p-value, considering the fact that the association between sRAGE and emphysema in the minor allele genotype in our study was not significant.

Our study had several strengths. This was the first study to simultaneously elucidate the associations among emphysema, sRAGE, and polymorphisms of the AGER gene. Although robust associations have been identified between pairs of these three factors, contradictions have emerged when emphysema and sRAGE are simultaneously linked with $A G E R$ genetics. Our study suggests a potential solution for understanding the association between sRAGE and emphysema in relation to AGER genetics. Furthermore, to our knowledge, no previous study has assessed sRAGE and emphysema in an Asian population.

There are several limitations to the current study. First, owing to the study design, it was impossible to assess temporal relationships among the factors. Further studies are needed to prove the temporal relationship between the AGER gene, sRAGE, and emphysema. Second, there was no difference in sRAGE levels between COPD and non-COPD patients, unlike the findings presented in several studies [4, 32, 33]. Since the studies showed that sRAGE levels are associated with not only the presence of COPD but also the severity of COPD, this might be due to the milder COPD in the majority of our study participants compared to the previous studies. In line with previous studies, our results show that the $\mathrm{T}$ allele of rs2070600 is associated with a lower risk of COPD and mild COPD [34-36]. The distribution of the rs 2070600 polymorphism was considerably different from that reported in studies of other ethnicities [37, 38]. However, this is in line with previous Asian studies, including studies on the Korean population, and the distribution of $A G E R$ polymorphisms is well known to differ between ethnic groups $[25,39,40]$. This makes it difficult to apply the results to other ethnicities, and further studies are required for validation in other populations. In statistical analysis, multiple comparisons problem which is made in univariable regression analyses can be an another limitation. Finally, since these results are the first identified results, external replications are needed in larger and different cohorts.

\section{Conclusion}

In conclusion, our study showed that the protective effect of plasma sRAGE on emphysema is valid in participants with the CC genotype of rs2070600 on the AGER gene. These findings will provide information about future target groups for the prediction and treatment of emphysema.
Abbreviations

AGER: Advanced glycation end-product specific receptor; BMI: Body mass index; Cl: Confidence interval; COPD: Chronic obstructive pulmonary disease; CT: Computed tomography; ELISA: Enzyme-linked immunosorbent assay; $\mathrm{FEV}_{1}$ : Forced expiratory volume in one second; FVC: Forced vital capacity; GOLD: Global initiative on obstructive lung disease; GWAS: Genome-wide association studies; SRAGE: Soluble receptor for advanced glycation end product.

\section{Supplementary Information}

The online version contains supplementary material available at https://doi. org/10.1186/s12890-022-01848-9.

Additional file 1. Fig. 1. Distribution of plasma SRAGE level and logtransformed sRAGE level.

\section{Acknowledgements}

Not applicable.

\section{Authors' contributions}

W.J.K contributed to the study concept and design, interpretation, review, and revision of the manuscript; S.S. contributed to the literature search, interpretation, review, writing, and revision of the manuscript; M.L. and J.K. contributed to the collection and analysis of data; S.H.B contributed to the study design and data collection. All authors provided final approval for publication submission and critically revised the manuscript for important intellectual content.

\section{Funding}

This research received no funding.

\section{Availability of data and materials}

The datasets used and/or analysed during the current study are available from the corresponding author upon reasonable request.

\section{Declarations}

\section{Ethics approval and consent to participate}

This study was approved by the Institutional Review Board of the Kangwon National University Hospital (IRB No. KNUH 2012-06-007). Written informed consent was obtained from all participants.

\section{Consent for publication}

Not applicable.

\section{Competing interests}

The authors declare that they have no competing interests.

\section{Author details}

${ }^{1}$ Department of Internal Medicine, School of Medicine, Kangwon National University Hospital, Kangwon National University, Chuncheon 24341, Republic of Korea. ${ }^{2}$ Department of Internal Medicine and Environmental Health Center, School of Medicine, Kangwon National University Hospital, Kangwon National University, Chuncheon, Republic of Korea. ${ }^{3}$ Department of Radiology, School of Medicine, Kangwon National University Hospital, Kangwon National University, Chuncheon, Republic of Korea.

Received: 4 May 2021 Accepted: 31 January 2022

Published online: 10 February 2022

\section{References}

1. Vogelmeier CF, Criner GJ, Martinez FJ, Anzueto A, Barnes PJ, Bourbeau J, et al. Global strategy for the diagnosis, management, and prevention of chronic obstructive lung disease 2017 report. GOLD executive summary. Am J Respir Crit Care Med. 2017;195(5):557-82. 
2. Johannessen A, Skorge TD, Bottai M, Grydeland TB, Nilsen RM, Coxson H, et al. Mortality by level of emphysema and airway wall thickness. Am J Respir Crit Care Med. 2013;187(6):602-8.

3. Oelsner EC, Hoffman EA, Folsom AR, Carr JJ, Enright PL, Kawut SM, et al. Association between emphysema-like lung on cardiac computed tomography and mortality in persons without airflow obstruction: a cohort study. Ann Intern Med. 2014;161(12):863-73.

4. Cheng DT, Kim DK, Cockayne DA, Belousov A, Bitter H, Cho MH, et al. Systemic soluble receptor for advanced glycation endproducts is a biomarker of emphysema and associated with AGER genetic variants in patients with chronic obstructive pulmonary disease. Am J Respir Crit Care Med. 2013;188(8):948-57.

5. Cockayne DA, Cheng DT, Waschki B, Sridhar S, Ravindran P, Hilton $\mathrm{H}$, et al. Systemic biomarkers of neutrophilic inflammation, tissue injury and repair in COPD patients with differing levels of disease severity. PLOS ONE. 2012;7(6):e38629.

6. Carolan BJ, Hughes G, Morrow J, Hersh CP, O'Neal WK, Rennard S, et al. The association of plasma biomarkers with computed tomographyassessed emphysema phenotypes. Respir Res. 2014;15:127.

7. Coxson HO, Dirksen A, Edwards LD, Yates JC, Agusti A, Bakke P, et al. The presence and progression of emphysema in COPD as determined by CT scanning and biomarker expression: a prospective analysis from the Eclipse study. Lancet Respir Med. 2013;1 (2):129-36.

8. Xie J, Méndez JD, Méndez-Valenzuela V, Aguilar-Hernández MM. Cellular signalling of the receptor for advanced glycation end products (RAGE). Cell Signal. 2013;25(11):2185-97.

9. Cipollone F, lezzi A, Fazia M, Zucchelli M, Pini B, Cuccurullo C, et al. The receptor RAGE as a progression factor amplifying arachidonate-dependent inflammatory and proteolytic response in human atherosclerotic plaques: role of glycemic control. Circulation. 2003;108(9):1070-7.

10. Hofmann MA, Drury S, Hudson BI, Gleason MR, Qu W, Lu Y, et al. RAGE and arthritis: the G82S polymorphism amplifies the inflammatory response. Genes Immun. 2002;3(3):123-35.

11. Durning SP, Preston-Hurlburt P, Clark PR, Xu D, Herold KC, Type 1 Diabetes TrialNet Study Group. The receptor for advanced glycation endproducts drives $T$ cell survival and inflammation in type 1 diabetes mellitus. J Immunol. 2016;197(8):3076-85.

12. Sanders KA, Delker DA, Huecksteadt T, Beck E, Wuren T, Chen Y, et al. RAGE is a critical mediator of pulmonary oxidative stress, alveolar macrophage activation and emphysema in response to cigarette smoke. Sci Rep. 2019;9:231.

13. Lee H, Park JR, Kim WJ, Sundar IK, Rahman I, Park SM, et al. Blockade of RAGE ameliorates elastase-induced emphysema development and progression via RAGE-DAMP signaling. FASEB J. 2017;31(5):2076-89.

14. Stogsdill MP, Stogsdill JA, Bodine BG, Fredrickson AC, SefcikTL, Wood TT, et al. Conditional overexpression of receptors for advanced glycation end-products in the adult murine lung causes airspace enlargement and induces inflammation. Am J Respir Cell Mol Biol. 2013;49(1):128-34.

15. Cho MH, Castaldi PJ, Hersh CP, Hobbs BD, Barr RG, Tal-Singer R, et al. A genome-wide association study of emphysema and airway quantitative imaging phenotypes. Am J Respir Crit Care Med. 2015;192(5):559-69.

16. Hobbs BD, de Jong K, Lamontagne M, Bossé Y, Shrine N, Artigas MS, et al. Genetic loci associated with chronic obstructive pulmonary disease overlap with loci for lung function and pulmonary fibrosis. Nat Genet. 2017:49(3):426-32.

17. Lee H, Hong Y, Lim MN, Bak SH, Kim MJ, Kim K, et al. Inflammatory biomarkers and radiologic measurements in never-smokers with COPD: a cross-sectional study from the CODA cohort. Chron Respir Dis. 2018;15(2):138-45.

18. Oh YM, Lee KS, Hong Y, Hwang SC, Kim JY, Kim DK, et al. Blood eosinophil count as a prognostic biomarker in COPD. Int J Chron Obstruct Pulm Dis. 2018;13:3589-96.

19. Washko GR, Hunninghake GM, Fernandez IE, Nishino M, Okajima Y, Yamashiro $T$, et al. Lung volumes and emphysema in smokers with interstitial lung abnormalities. N Engl J Med. 2011;364(10):897-906.

20. Wang Z, Gu S, Leader JK, Kundu S, Tedrow JR, Sciurba FC, et al. Optimal threshold in CT quantification of emphysema. Eur Radiol. 2013;23(4):975-84.

21. Miller S, Henry AP, Hodge E, Kheirallah AK, Billington CK, Rimington TL, et al. The Ser82 RAGE variant affects lung function and serum RAGE in smokers and sRAGE production in vitro. PLOS ONE. 2016;11(10):e0164041.
22. Occhipinti M, Paoletti M, Bartholmai BJ, Rajagopalan S, Karwoski RA, Nardi $C$, et al. Spirometric assessment of emphysema presence and severity as measured by quantitative CT and CT-based radiomics in COPD. Respir Res. 2019;20(1):101.

23. Bak SH, Kwon SO, Han SS, Kim WJ. Computed tomography-derived area and density of pectoralis muscle associated disease severity and longitudinal changes in chronic obstructive pulmonary disease: a case control study. Respir Res. 2019;20(1):226.

24. Hofmann MA, Drury S, Fu C, Qu W, Taguchi A, LuY, et al. RAGE mediates a novel proinflammatory axis: a central cell surface receptor for $\mathrm{S100/}$ calgranulin polypeptides. Cell. 1999;97(7):889-901.

25. Waseda K, Miyahara N, Taniguchi A, Kurimoto E, Ikeda G, Koga H, et al. Emphysema requires the receptor for advanced glycation end-products triggering on structural cells. Am J Respir Cell Mol Biol. 2015;52(4):482-91.

26. Sambamurthy N, Leme AS, Oury TD, Shapiro SD. The receptor for advanced glycation end products (RAGE) contributes to the progression of emphysema in mice. PLOS ONE. 2015;10(3):e0118979.

27. Blondonnet R, Audard J, Belville C, Clairefond G, Lutz J, Bouvier D, et al. RAGE inhibition reduces acute lung injury in mice. Sci Rep. 2017;7:7208.

28. Cao X, Lin L, Sood A, Ma Q, Zhang X, Liu Y, et al. Small airway wall thickening assessed by computerized tomography is associated with low lung function in Chinese carbon black packers. Toxicol Sci. 2020;178:26-35.

29. Jang Y, Kim JY, Kang SM, Kim JS, Chae JS, Kim OY, et al. Association of the Gly82Ser polymorphism in the receptor for advanced glycation end products (RAGE) gene with circulating levels of soluble RAGE and inflammatory markers in nondiabetic and nonobese Koreans. Metabolism. 2007;56(2):199-205.

30. Hoonhorst SJ, Lo Tam Loi AT, Pouwels SD, Faiz A, Telenga ED, van den Berge $\mathrm{M}$, et al. Advanced glycation endproducts and their receptor in different body compartments in COPD. Respir Res. van den Berge M, editors. 2016;17:46.

31. Pratte KA, Curtis JL, Kechris K, Couper D, Cho MH, Silverman EK, et al. Soluble receptor for advanced glycation end products (SRAGE) as a biomarker of COPD. Respir Res. 2021;22(1):127.

32. Gopal P, Rutten EP, Dentener MA, Wouters EF, Reynaert NL. Decreased plasma sRAGE levels in COPD: influence of oxygen therapy. Eur J Clin Investig. 2012;42(8):807-14.

33. Smith DJ, Yerkovich ST, Towers MA, Carroll ML, Thomas R, Upham JW. Reduced soluble receptor for advanced glycation end-products in COPD. Eur Respir J. 2011;37(3):516-22.

34. Repapi E, Sayers I, Wain LV, Burton PR, Johnson T, Obeidat M, et al. Genome-wide association study identifies five loci associated with lung function. Nat Genet. 2010;42(1):36-44

35. Young RP, Hopkins RJ, Whittington CF, Hay BA, Epton MJ, Gamble GD. Individual and cumulative effects of GWAS susceptibility loci in lung cancer: associations after sub-phenotyping for COPD. PLOS ONE. 2011;6(2):e16476

36. Hancock DB, Eijgelsheim M, Wilk JB, Gharib SA, Loehr LR, Marciante KD, et al. Meta-analyses of genome-wide association studies identify multiple loci associated with pulmonary function. Nat Genet. 2010;42(1):45-52.

37. Gaens KH, Ferreira I, van der Kallen CJ, van Greevenbroek MM, Blaak $\mathrm{EE}$, Feskens EJ, et al. Association of polymorphism in the receptor for advanced glycation end products (RAGE) gene with circulating RAGE levels. J Clin Endocrinol Metab. 2009;94(12):5174-80.

38. Mehta R, Shaw G, Masschelin P, Felix S, Otgonsuren M, Baranova A, et al. Polymorphisms in the receptor for advanced glycation end-products (RAGE) gene and circulating RAGE levels as a susceptibility factor for nonalcoholic steatohepatitis (NASH). PLOS ONE. 2018;13(6):e0199294.

39. LiT, Qin W, Liu Y, Li S, Qin X, Liu Z. Effect of RAGE gene polymorphisms and circulating SRAGE levels on susceptibility to gastric cancer: a casecontrol study. Cancer Cell Int. 2017;17(1):19.

40. Yamaguchi K, Iwamoto H, Horimasu Y, Ohshimo S, Fujitaka K, Hamada $\mathrm{H}$, et al. AGER gene polymorphisms and soluble receptor for advanced glycation end product in patients with idiopathic pulmonary fibrosis. Respirology. 2017;22(5):965-71.

\section{Publisher's Note}

Springer Nature remains neutral with regard to jurisdictional claims in published maps and institutional affiliations. 